\title{
OPEM
}

www.opem.org

Oriental Pharmacy and Experimental Medicine 2009 9(4), 335-338

DOI 10.3742/OPEM.2009.9.4.335

\section{Antiarthritic action of polar fraction from Sida rhombifolia aerial parts}

\author{
SR Gupta, SA Nirmal* and RY Patil \\ Department of Pharmacognosy, Pravara Rural College of Pharmacy, Loni, MS, India
}

Received for publication April 17, 2008; accepted April 17, 2009

\begin{abstract}
SUMMARY
Aerial parts of Sida rhombifolia Linn. (Malvaceae) were extracted successively using various solvents and screened for various parameters of antiarthritic activity such as adjuvant-induced arthritis, motor performance, and histopathological study. The ethanol and the aqueous extracts showed potent activity; further these extracts were fractionated by using column chromatography. The fraction ET1 isolated from ethanol extract showed the most potent antiarthritic activity.
\end{abstract}

Key words: Sida rhombifolia; Antiarthritic activity; Complete Freund's adjuvant; Column chromatography

\section{INTRODUCTION}

Sida (S.) rhombifolia L. syn S. orientalis (Malvaceae) is small erect undershrub traditionally used as a nutritive, tonic, in the treatment of gonorrhea, piles, rheumatism and as a diuretic and an aphrodisiac (Nadkarni, 1982). Traditionally root is used as antibacterial, antipyretic, and antimalerial agent. Flowers are used in labor pain and toothache and leaves are used to induce abortion (Anonymous, 2005). $\beta$-phenethylamine, $N$-methyl $\beta$-phenethylamine, S-(+) N- $\beta$-methyl tryptophan methyl ester, vasicinol, vasicinone, vasicine, choline, hypaphorine methyl ester, hypaphorine, and betaine were identified from this plant (Rastogi and Mehrotra, 1993).

Alcohol extract of roots of $S$. rhombifolia showed anti-inflammatory activity in cotton pellet granuloma model and antipyretic activity in typhoid paratyphoid A and B vaccine induced pyrexia (Alam et al., 1991). Ethyl acetate extract of leaves of S. rhombifolia

\footnotetext{
*Correspondence: SA Nirmal, Department of Pharmacognosy, Pravara Rural College of Pharmacy, Loni, MS, India. E-mail: nirmalsunil@rediffmail.com
}

showed potent cytotoxicity activity (Islam et al., 2003). Alcohol extract of whole plant of S. rhombifolia inhibited the growth of $P$. aeruginosa, S. paratyphi A, S. albus, S. aureus, S. citreus and B. subtilis (Alam et al., 1991). Fatty acids from the leaves of the plant exhibited antibacterial activity in cup plate method (Bhatt et al., 1983).

To the best of our knowledge no pharmacological work regarding antiarthritic activity of S. rhombifolia aerial parts has been reported. In the present study, an effort has been made to establish the scientific validity of antiarthritic property of $S$. rhombifolia.

\section{MATERIALS AND METHODS}

\section{Plant material}

Fresh aerial parts of $S$. rhombifolia were collected in April 2006 from local area of Ahmednagar district, Maharashtra, India and authenticated by Dr. P.S.N. Rao, Botanical Survey of India, Pune. A voucher specimen (SRSG1) is being maintained. The aerial parts were separated and allowed for shade drying and stored in form of moderately coarse powder. 


\section{Extraction}

Powdered aerial part $(500 \mathrm{~g})$ of the plant was successively extracted with petroleum ether (60 $80^{\circ} \mathrm{C}$ ), chloroform, ethyl acetate, and ethanol using Soxhlet extractor. Finally the marc left was refluxed with water to obtain aqueous extract. All the extracts were vacuum dried to yield PEE $(1.3 \% \mathrm{w} / \mathrm{w})$, CLE $(2.0 \% \mathrm{w} / \mathrm{w}), \operatorname{EAE}(0.18 \% \mathrm{w} / \mathrm{w}), \operatorname{ETE}(1.85 \%$ $\mathrm{w} / \mathrm{w})$, and AQE $(16.92 \% \mathrm{w} / \mathrm{w})$, respectively.

\section{Column chromatography}

Based on primary pharmacological screening of crude extracts, ethanol and aqueous extracts were most active and hence subjected to column chromatography. Ethanol extract $(5.1 \mathrm{~g})$ of $S$. rhombifolia aerial parts was dissolved in small volume of ethanol-water (1:1) and applied to silica gel column $(2.9 \times 44 \mathrm{~cm})$, which was eluted by using ethyl acetate:methanol (9:1) yielding ET1 $(30.23 \%)$, further eluted with ethyl acetate:methanol (2:8) yielding ET2 (28.21\%), and lastly with methanol yielding ET3 (35.46\%).

Aqueous extract $(3.5 \mathrm{~g})$ of S. rhombifolia aerial parts was dissolved in small volume of ethanolwater (1:1) and applied to silica gel column $(2.9 \times$ $44 \mathrm{~cm}$ ), which was eluted by methanol:water (9:1) yielding AQ1 (25.08\%), further eluted with methanol: water (8:2) yielding AQ2 (32.56\%), and lastly with water yielding AQ3 (37.12\%).

\section{Drugs and chemicals}

The following drugs and chemicals were used. Drugs : Diclofenac sodium (Voveran, India) and Complete Freund's adjuvant (Difco. In., USA). Chemicals: Petroleum ether $\left(60-80^{\circ} \mathrm{C}\right)$ (PCL, India), Chloroform (PCL, India), Ethyl acetate (PCL, India), Ethanol (PCL, India), and Tween 80 (PCL, India).

\section{Animals}

Male Wistar rats 10 - 12 weeks old (150 - 200 g) were used in all experimental protocols. Animals were maintained under standard environmental conditions and had free access to standard feed and water ad libitum during study. Animal Ethical Committee approved all the experimental protocols and procedures (Approval no. PRCOP/25).

\section{Adjuvant induced arthritis}

The activity was performed as described by Pearson and Wood (1959). Animals were divided into 13 groups. Control group received vehicle (1\% tween 80 in distilled water), second to sixth groups received PEE, CLE, EAE, ETE, and AQE (100 mg/ $\mathrm{kg}$, p.o., each), seventh to twelfth group received ET1, ET2, ET3, AQ1, AQ2, and AQ3 $(10 \mathrm{mg} / \mathrm{kg}$, p.o., each), and thirteenth group received standard drug diclofenac sodium ( $13.5 \mathrm{mg} / \mathrm{kg}$, p.o.).

On 0th day left hind paw volume of all animals was measured using digital plethysmometer (Panlab S.J LE 7500). Arthritis was induced in all animals on 1st day by injecting $0.1 \mathrm{ml}$ of CFA into the subplanter region of left hind paw. The dosing of all the extracts was started on 1st day to the respective group and continued till 14th day. The assessment of antiarthritic activity was done by measuring the mean change in paw edema on 4th, 8th, 12th, and 16th day after induction.

\section{Motor performance}

In order to evaluate non-specific muscle relaxant effect of S. rhombifolia extracts, rats were tested on rota rod (Dunham and Miya, 1956). The animals were trained for three days before the assay and the rats that did not remain on the rod for $120 \mathrm{~s}$ (cut-off time) were eliminated from the experiment. Such prescreened rats were divided into thirteen groups and treated as described above. On 4th, 8th, 12th, and 16th day after arthritis induction the time required to fall the animals from rotating bar was recorded.

\section{Histopathological study}

Morphometric analysis of histological sections of knee joints is essential for quantifying degree of joint damage and drug efficacy in animal model of 
arthritis. It is of particular interest to measure integrity of synovium. Here the animals developing arthritis were sacrificed by ether inhalation. Their left knee joints were removed and decalcified for 3 days with formic acid, fixed in formalin and embedded in paraffin. Sections of complete knee joints were stained with haematoxyline-eosine and images of sections were taken (Guhring et al., 2006).

\section{Statistical analysis}

Data are reported as means \pm S.E.M. ( $n=5$ animals per group) and analyzed statistically by one-way ANOVA followed by Dunnett's test. ${ }^{*} P<0.05$ was taken as statistically significant.

\section{RESULTS}

\section{Adjuvant induced arthritis}

CFA induced a significant paw edema on 4th day in control group, which persisted till 16th day. The fractions reduced paw edema volume significantly gradually till 16th day in order as ET1, AQ1, ET2, ET3, and AQ2 (Fig. 1). The fraction AQ3 was not significant (data not shown).

\section{Motor performance}

The fractions significantly reduced time required to fall the animals from rotating bar in the order as ET1, ET2, ET3, and AQ1 (Fig. 2). AQ2 and AQ3

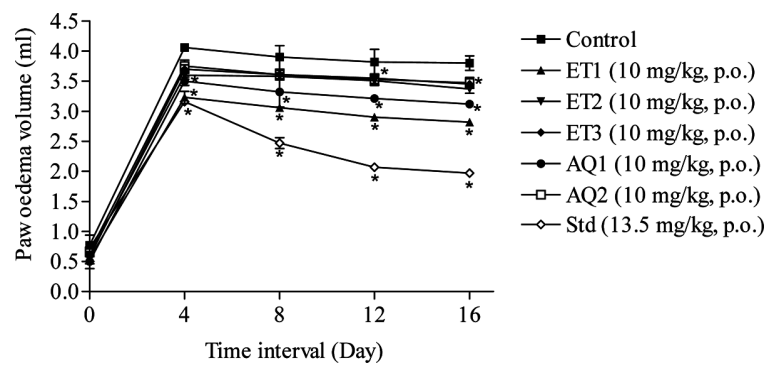

Fig. 1. Effect of various fractions of ethanol and aqueous extracts of aerial parts of $S$. rhombifolia in adjuvant-induced arthritis model in rats using plethysmometer. Results are expressed as mean \pm S.E.M. from five observations; ${ }^{*} P<0.05$ significant compared with control group. Nonsignifacant data is not shown.

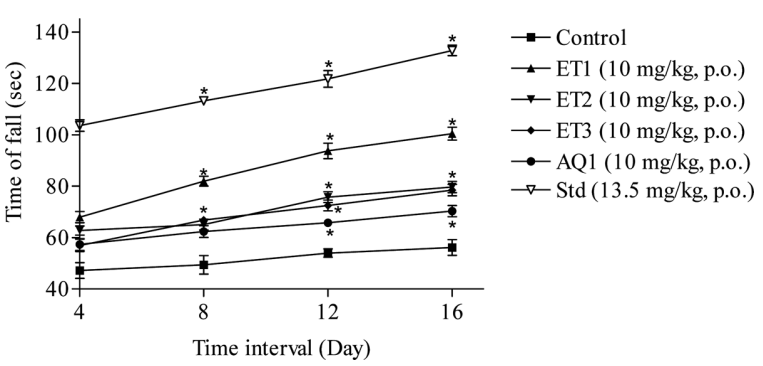

Fig. 2. Effect of various fractions of ethanol and aqueous extracts of $S$. rhombifolia aerial parts on time of fall using rota rod apparatus. Results are expressed as mean \pm S.E.M. from five observations; ${ }^{*} P<0.05$ significant compared with control group. Nonsignifacant data is not shown.

were not significant (data not shown).

\section{Histopathological study}

Section from the ET1 showed minimal damage, stroma was unremarkable. Section from ET2 showed normal synovial tissue, stroma showed fibrosis with edema. Section from ET3 showed mild neutrophilic infiltrate with synovial tissue, stroma showed diffuse lymphocyte with edema. Section from AQ1 showed moderate distorted synovial tissue. Section from AQ2 showed majorly damaged synovial tissue, stroma showed lymphatic infiltrate. Section from AQ3 showed completely distorted synovial tissue, stroma showed moderate lymphocytic infiltrate with macrophages. Section from the control revealed synovial tissue with dense damage, stroma showed diffuse infiltration by neutrophils and macrophages. Lining epithelium is distorted. Section from the standard revealed normal synovium (Fig. 3).

From the results of adjuvant induced arthritis, motor performance, and histopathological study, it can be concluded that the fraction ET1 isolated by column chromatography from ethanol extract of $S$. rhombifolia aerial parts by eluting in the mobile phase ethyl acetate:methanol (9:1) is most active as antiarthritic agent. Alam et al. (1991) showed that alcoholic extract of $S$. rhombifolia is having significant anti-inflammatory activity so this going to support 

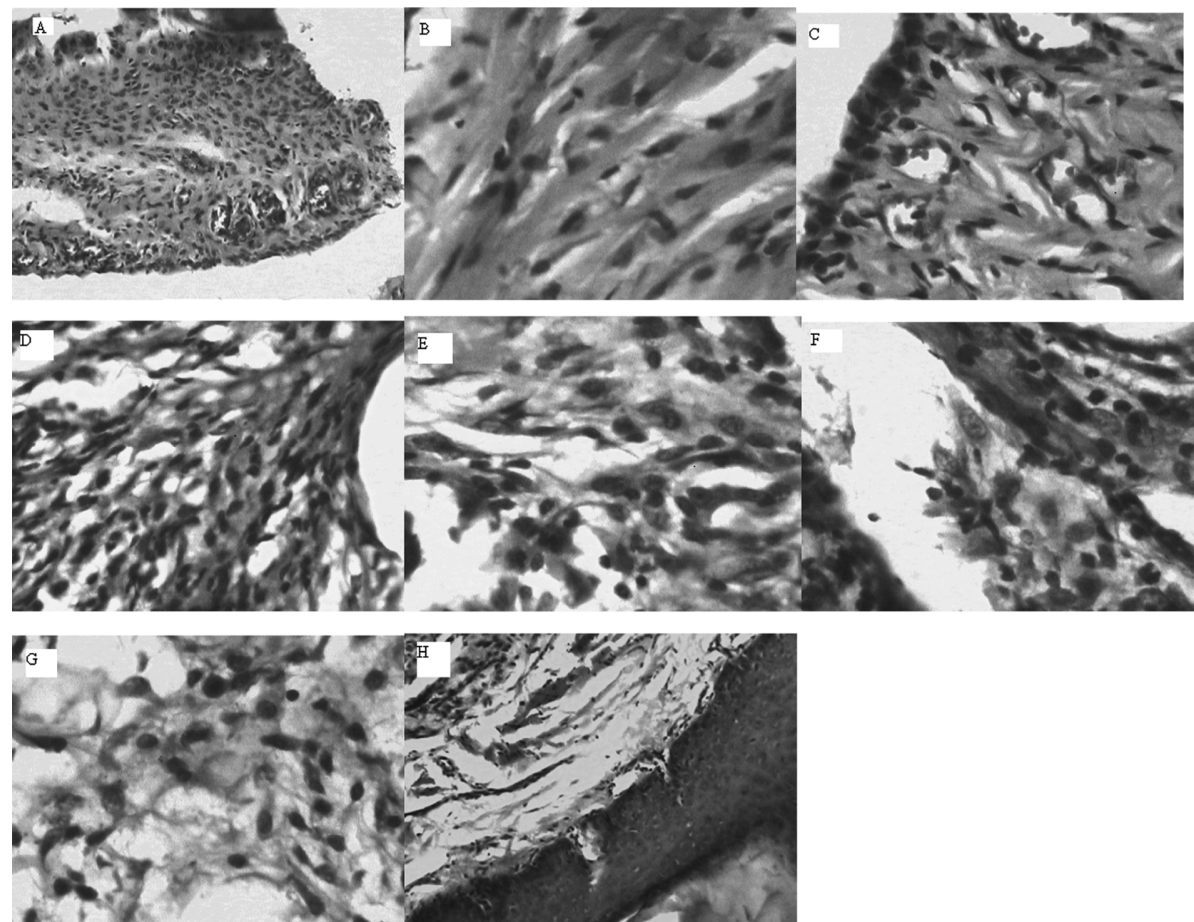

Fig. 3. Section of synovium from knee joint of rat treated with various fraction of $S$. rhombifolia aerial parts. A, ET1 fraction; B, ET2 fraction; C, ET3 fraction; D, AQ1 fraction; E, AQ 2 fraction; F, AQ 3 fraction; G, vehicle; H, standard.

the possible antiarthritic action of fraction isolated from ethanol extract.

\section{REFERENCES}

Alam M, Joy S, Ali SU. (1991) Antibacterial activity of Sida cordifolia linn., Sida rhomboidea Roxb. and Triumfetta rotundifolia Lam. Indian Drugs 28, 570-572.

Alam M, Joy S, Ali SU. (1991) Screening of Sida cordifolia linn., Sida rhombifolia and Triumfetta rotundifolia for anti-inflammatory and antipyretic drugs. Indian Drugs 28, 397-399.

Anonymous. (2005) The Wealth of India. Council of Scientific and Industrial Research, New Delhi 1, 87.

Bhatt DJ, Baxi AJ, Parikh AR. (1983) Chemical investigations of leaves of Sida rhombifolia Linn. J. Indian Chem. Soc. 60, 98.

Dunham NW, Miya TS. (1957) A note on a simple apparatus for detecting neurological deficit in rats and mice. J. Am. Pharmaceut. Assoc. 46, 208-210.

Guhring H, Jensen T, Dore J, Grunkin M, Rudolphi K. (2006) Automated histomorphometric analysis of joint damage in mouse model of osteoarthritis. Aventis 34, 23.

Islam ME, Haque ME, Mosaddik MA. (2003) Cytotoxicity and antibacterial activity of Sida rhombifolia (Malvacae) grown in Bangladesh. Phytother. Res. 17, 973-975.

Nadkarni KM. (1982) Indian Materia Medica. Bombay Popular Prakashan, Bombay 3, 1138.

Pearson CM, Wood FD. (1959) Studies on polyarthritis and other lesions induced in rats by injection of mycobacterium adjuvant. I. General clinic and pathological characteristics and some modifying factors. Arthr. Rheum. 2, 440-459.

Rastogi RP, Mehrotra BN. (1993) Compendium of Indian Medicinal Plants. Central Drug Research Institute, Lucknow 1, 586. 